\title{
Pathophysiological basis for thyrotoxicosis as an aggravating factor in post-ischemic brain injury in rats
}

\author{
Leena Rastogi, Sushil Gupta and Madan M Godbole \\ Department of Endocrinology, Sanjay Gandhi Postgraduate Institute of Medical Sciences, Lucknow 226 014, India \\ (Correspondence should be addressed to M M Godbole; Email: madangodbole@yahoo.co.in)
}

\begin{abstract}
The cross-sectional epidemiological studies investigating hyperthyroidism as a risk factor for hypertension and stroke are not conclusive. Several case studies, however, indicate that persistent thyrotoxicosis aggravates neurological damage subsequent to a stroke. To test the hypothesis, we measured physiological and biochemical parameters in a model of transient focal ischemia in rats with prior induction of thyrotoxicosis to investigate its effects. Age- and weight-matched rats were made hyperthyroid prior to middle cerebral artery (MCA) occlusion and killed after 3 days of reperfusion. We then estimated neurological deficit scores, body temperature, circulating total and free thyroxine $\left(\mathrm{fT}_{4}\right)$ levels, lipid peroxide and thiol levels, and lactate dehydrogenase activity. While the standard 2-h occlusion of MCA resulted in very high mortality in
\end{abstract}

hyperthyroid animals, the 30-min MCA occlusion resulted in a significant increase in neurological deficits compared with sham-operated animals. We observed a twofold or more increase in circulating $\mathrm{fT}_{4}$ levels in rats receiving thyroxine. The increase in infarct size directly correlated with the increased dose of thyroxine. A significant thyroxine dose-dependent increase in lipid peroxide (malondialdehyde levels, $P<0 \cdot 05$ ), lactate dehydrogenase activity $(P<0 \cdot 01)$, and a significant decrease in protective thiol levels $(P<0 \cdot 05)$ were observed. The data support our hypothesis that thyrotoxicosis is an independent risk factor which contributes to the aggravation of post-stroke injury and death. The study results indicate a need to control thyrotoxicosis in elderly populations to reduce the risk.

Journal of Endocrinology (2008) 196, 335-341

\section{Introduction}

Acute ischemic stroke is a leading cause of death and longterm disability in adults. In spite of a large body of work, the pathophysiology involved in ischemic strokes is far from clear. Several conditions such as hypertension, atherosclerosis, diabetes mellitus, and genetic and other factors are identified as risk factors in the etiology of strokes. To what extent these factors contribute to the aggravation of stroke-induced injury and neurological deficits is still not clear. Circulating thyroid hormone (TH) levels seem to modulate the outcome of ischemic-reperfusion (IR) injury and hypothyroidism is shown to be neuroprotective in the animal stroke model as well as in stroke patients (Shuaib et al. 1994, Alevizaki et al. 2006, Rastogi et al. 2006). In contrast, thyrotoxicosis causes oxidative damage in various tissues such as the liver, heart, and brain of the rats (Adamo et al. 1989). The risk of dementia and Alzheimer's disease is greater in hyperthyroid patients (Kalmijn 2000, Kapaki et al. 2006). In thyrotoxicosis, atrial fibrillation and cardioembolic stroke can precipitate acute cerebral ischemia, and oxidative stress along with lipid peroxidation damage have been suggested as plausible mechanisms (Squizzato et al. 2005). In a clinical-experimental study, chronic thyrotoxicosis in patients has been reported to aggravate the symptoms of hypertensive disease and increased oxygen consumption by tissues, slowed down the electron transport from the respiratory chain, and increased the content of iodine and protein, (Bulesta et al. 1981). Though cross-sectional studies in elderly populations are not able to ascertain a clear relationship between thyrotoxicosis, hypertension and strokes (Qureshi et al. 2006, Völzke et al. 2006, Walsh et al. 2006, Wilson et al. 2006), clinical case reports suggest that thyrotoxicosis aggravates neurological damage subsequent to cerebral ischemia (Smith et al. 1994, Rocha et al. 2001, Mouton et al. 2005, Tsai et al. 2006). In a case of Grave's disease with frequent episodic transient left hemiparesis and mild slurred speech lasting for a few minutes to $2 \mathrm{~h}$, the recurrence was prevented by treatment with propylthiouracil and aspirin (Tsai et al. 2006). The pathophysiological relationship between thyrotoxicosis and aggravation of ischemia-induced cerebral damage is not clear. In the present study, we investigated the effect of elevated circulating $\mathrm{TH}$ levels on the extent of post-ischemiareperfusion brain injury and the pathophysiological basis of neural damage using a model of focal ischemia in hyperthyroid rats. 


\section{Materials and Methods}

\section{Animals and experimental protocol}

Male Sprague-Dawley albino rats $(n=75$, weight $250-350 \mathrm{~g})$ were housed at a temperature of $25 \pm 2{ }^{\circ} \mathrm{C}$ with an alternating $12 \mathrm{~h}$ light: $12 \mathrm{~h}$ darkness cycle and access to standard food pellets and water ad libitum. The rats were divided into two groups: euthyroid $(n=15)$ and thyrotoxic $(n=60)$. The rats were rendered thyrotoxic by administration of different doses of L-thyroxine (L- $\mathrm{T}_{4} ; 1 \cdot 5,4 \cdot 5,7 \cdot 5$, and $10 \mu \mathrm{g} / 100 \mathrm{~g}$ body weight (BW), i.p., daily, $n=15$ for each dose) for 7 days. In initial experiments, euthyroid animals $(\mathrm{E}+\mathrm{IR}, n=3)$ and animals which received different doses of $\mathrm{L}-\mathrm{T}_{4}(\mathrm{~T}+\mathrm{IR}, n=3$, for each dose) underwent $2 \mathrm{~h}$ of ischemia followed by reperfusion. Since $2 \mathrm{~h}$ of middle cerebral artery (MCA) occlusion caused $100 \%$ mortality within $24 \mathrm{~h}$ of reperfusion in $\mathrm{T}_{4}$-treated rats, the MCA occlusion time was reduced to 30 min wherein no mortality was observed in $\mathrm{T}_{4}$-treated rats, even after 3 days following reperfusion. This modified the protocol in which euthyroid animals (E+IR, $n=6)$ and thyrotoxic animals that received different doses of $\mathrm{L}-\mathrm{T}_{4}(\mathrm{~T}+$ IR, $n=6$, for each dose) underwent $30 \mathrm{~min}$ of transient ischemia followed by reperfusion. This was done to assess the impact of thyrotoxicosis on day 3. A sham procedure was also performed both in euthyroid rats $(\mathrm{E}+\mathrm{S}, n=6)$ and in rats treated with different doses of $\mathrm{L}-\mathrm{T}_{4}(\mathrm{~T}+\mathrm{IR}, n=6$, for each dose). The core body temperature was monitored manually using a thermoprobe temporarily inserted $2 \mathrm{~cm}$ into the rectum in each group of rats. Serum total and free $T_{4}$ levels were measured by RIA using kits from Diagnostic Product Company (Los Angeles, CA, USA).

\section{Transient focal ischemia}

Euthyroid rats and thyrotoxic rats were fasted overnight and anesthetized by an i.p. injection of chloral hydrate $300 \mathrm{mg} / 100 \mathrm{~g} \mathrm{BW}$. The core temperature (rectal) was maintained at $37 \pm 0.5{ }^{\circ} \mathrm{C}$ throughout the surgical procedure using a heating lamp. A midline incision was made and the right common, external, and internal carotid arteries were exposed. A 4-0 monofilament nylon thread (Ethical, Johnson \& Johnson), with its tip rounded by rapid heating, was used to occlude the MCA. The small segment of nylon filament adjusted according to the $\mathrm{BW}$ and varied from 20 to $22 \mathrm{~mm}$ was advanced from the external carotid artery into the lumen of the internal carotid artery until resistance was encountered, which ensured the occlusion of the origin of the MCA. The nylon filament was allowed to remain in place for $30 \mathrm{~min}$, after which it was gently retracted so as to allow for reperfusion (Zea-Longa et al. 1989). The sham-operated animals were subjected to the same surgical and anesthetic procedures used in the experimental IR groups but without intravascular insertion of the filament into the lumen of the artery.
Neurological evaluation

All the animals were subjected to neurological evaluation by using a 6-point postural reflex test (Bederson et al. 1986) every $24 \mathrm{~h}$ for 3 days after ischemia-reperfusion. Briefly, scoring was as follows: no deficit, 0; failure to extend left forepaw, 1; circling to the left while pulled by tail, 2; paresis of the left side, 3; no spontaneous walking, 4; and death, 5 .

\section{Blood collection and tissue sampling}

Following neurological evaluation, rats were anesthetized and blood was collected for hormonal and enzymatic assays. Subsequent to blood sampling, rats were killed by decapitation. Brains were harvested for the 2,3,5-triphenyl tetrazolium chloride (TTC) staining in fresh tissue $(n=3)$. The rest of the brain tissue $(n=3)$ was stored at $-70^{\circ} \mathrm{C}$ for the estimation of reduced glutathione (GSH) and malondialdehyde (MDA) to assess the effect of injury from each group of rats. All animal procedures were in strict accordance with the institutional guidelines for animal care and research and approved by the animal ethics committee of Sanjay Gandhi PostGraduate Institute of Medical Sciences.

\section{Infarct assessment and quantitation}

The forebrain was promptly removed and sliced into $2 \mathrm{~mm}$ thick coronal sections. Seven coronal brain sections were cut from freshly obtained and cleaned tissue and stained with TTC. All the slices were incubated for $30 \mathrm{~min}$ in a $2 \%$ solution of TTC at $37^{\circ} \mathrm{C}$ and fixed in a $10 \%$ paraformaldehyde solution. The infarct area in each section was determined using a computerized image analysis system (Biovis Image plus, Mumbai, India). The total infarct volume was calculated by summing up the infarct areas in each section and multiplying it by the slice thickness.

\section{Tissue processing and measurement of enzymatic activity}

Brain tissue stored at $-70{ }^{\circ} \mathrm{C}$ was slowly brought to $4{ }^{\circ} \mathrm{C}$ on ice. A $10 \%(\mathrm{w} / \mathrm{v})$ brain homogenate was prepared in phosphate buffer $(50 \mathrm{mM}, \mathrm{pH} 7 \cdot 0)$ under ice-cold condition using teflon homogenizer. The homogenate was centrifuged at $300 \boldsymbol{g}$ for 10 min at $4{ }^{\circ} \mathrm{C}$. In the supernatant, levels of protein, MDA, and GSH were measured.

\section{Measurement of tissue MDA and GSH}

MDA was determined by quantifying the reaction product with thiobarbituric acid in the tissue supernatant (Okhawa et al. 1979). The colored end product was read at $540 \mathrm{~nm}$. The results were expressed as nmol MDA/mg protein. Reduced GSH was measured in the tissue supernatant using dithiobis-2-nitrobenzoic acid reagent (Beutlin et al. 1969). The colored end product was read at $412 \mathrm{~nm}$ and the results were expressed as $\mu \mathrm{g} \mathrm{GSH} / \mathrm{mg}$ protein. 
Measurement of plasma lactate dehydrogenase (LDH)

LDH activity in plasma was estimated by the method of the oxidation of lactate to pyruvate with a simultaneous reduction of NAD to NADH (Wroblewski \& La Due 1955). The rate of NAD reduction was measured as an increase in absorbance at $340 \mathrm{~nm}$. The results were expressed as $\mathrm{U} / \mathrm{min}$ per $\mathrm{mg}$ plasma protein.

\section{Protein assay}

Protein was assayed in all tissue supernatants, and in plasma utilizing BSA as an external standard to express specific enzyme activity (Lowry et al. 1951).

\section{Statistical analysis}

Results of the quantitative parameters are presented as mean \pm s.D. and $n$ indicates the number of animals. Statistical comparisons were made using Student's $t$-test between two groups and one-way ANOVA for more than two groups. To find out group differences post hoc ANOVA was done using Student-Newman-Keul's test. $P<0 \cdot 05$ represents a level of significance.

\section{Results}

\section{General characteristic of thyrotoxic rats}

All $\mathrm{T}+\mathrm{S}$ and $\mathrm{T}+\mathrm{IR}$ group rats tolerated the treatment protocol and occlusion procedure well and there were no deaths encountered. Rats treated with different doses of $\mathrm{L}-\mathrm{T}_{4}$ showed signs of hyperactivity. Circulating total and free $T_{4}$ levels showed a significant dose-dependent increase in the group of rats administered $\mathrm{L}-\mathrm{T}_{4}$ treatment $(\mathrm{T}+\mathrm{S}$ and $\mathrm{T}+\mathrm{IR})$ when compared with euthyroid animals $(E+S$ and $E+I R)$. In the rats that received a daily dose of $\mathrm{L}-\mathrm{T}_{4}$ in a dose of $1.5 \mu \mathrm{g} / 100 \mathrm{~g} \mathrm{BW} /$ day, circulating total $\mathrm{T}_{4}$ and free $\mathrm{T}_{4}$ levels were comparable with euthyroid animals (Fig. 1A).

\section{Neurological evaluation}

Neurological evaluation was carried out on day 3 of both ischemia-reperfusion and sham-operated animals. No neurological deficits were observed in sham-operated rats $(E+S, T+S)$ except a mild one in the $10 \mu \mathrm{g} / 100 \mathrm{~g} \mathrm{~L}-\mathrm{T}_{4}$ treated group. A significant dose-dependent increase was seen in neurological deficits in thyrotoxic rats ( $T+I R)$ compared with either euthyroid animals $(E+S$ and $E+I R)$ or animals that received a daily dose of $\mathrm{L}_{-} \mathrm{T}_{4}$ at $1.5 \mu \mathrm{g} / 100 \mathrm{~g} \mathrm{BW}$ per day (Fig. 1B).

\section{Infarct assessment by 2,3,5-trimethyl tetrazolium chloride (TTC)}

On day 3, the extent of infarct was assessed by TTC stain in fresh brain tissue. A normal staining pattern of the viable brain tissue was observed in sham-operated rats $(\mathrm{E}+\mathrm{S}, \mathrm{T}+\mathrm{S})$ but not in rats receiving $\mathrm{L}-\mathrm{T}_{4}$ in the dose of $10 \mu \mathrm{g} / 100 \mathrm{~g} \mathrm{BW}$ per day, which showed partial infarct in the brain (Fig. 1B). The dose-dependent increase in infarct size and volume were observed in the right hemisphere of thyrotoxic rats (T + IR) but not in the IR group with the $\mathrm{L}_{-} \mathrm{T}_{4}$ dose of $1.5 \mu \mathrm{g} / 100 \mathrm{~g}$ $\mathrm{BW}$ when compared with euthyroid rats (E+IR; Fig. 1C and D). The infarct volume was found to be significantly increased at the $\mathrm{L}_{-} \mathrm{T}_{4}$ dose of $4 \cdot 5 \mu \mathrm{g} / 100 \mathrm{~g} \mathrm{BW}$ and higher $(P<0 \cdot 05)$.

\section{Effect of thyrotoxicosis on LDH activity}

Plasma LDH activity is a marker of cell death and is taken as an index of brain injury (Fig. 2A). A significant increase was observed in the LDH activity among thyrotoxic shamoperated rats compared with euthyroid rats $(\mathrm{T}+\mathrm{S}$ versus $\left.\mathrm{E}+\mathrm{S},{ }^{\mathbb{S}} \mathrm{P}<0 \cdot 05\right)$. This increase, however, was not dose dependent. The LDH activity increased significantly in the euthyroid ischemic-reperfused rats when compared with sham-operated rats ( $\mathrm{E}+\mathrm{IR}$ versus $\mathrm{E}+\mathrm{S}, \quad \$ P<0 \cdot 05)$. Ischemia-reperfusion produced a dose-dependent four- to five-fold increase in the activity of LDH in thyrotoxic rats when compared with euthyroid rats $(T+I R$ versus $E+I R$, $* * P<0 \cdot 01)$.

\section{Effect of thyrotoxicosis on change in $M D A$ content after $M C A$} occlusion

No significant differences were observed in MDA content either in sham-operated rats or in euthyroid rats on ischemia-reperfusion $(\mathrm{E}+\mathrm{S}, \mathrm{T}+\mathrm{S}$, and $\mathrm{E}+\mathrm{IR})$. Ischemiareperfusion significantly increased brain MDA content in thyrotoxic rats when compared with euthyroid rats $(T+I R$ versus $\mathrm{E}+\mathrm{IR},{ }^{*} \mathrm{P}<0 \cdot 05$; Fig. $\left.2 \mathrm{~B}\right)$.

\section{Effect of thyrotoxicosis on tissue GSH level}

An increase in reduced GSH is an index of protective mechanism. No significant decrease was observed in the GSH content of the sham-operated rats and euthyroid ischemicreperfused rats $(\mathrm{E}+\mathrm{S}, \mathrm{T}+\mathrm{S}$, and $\mathrm{E}+\mathrm{IR}$, Fig. 2C). However, in thyrotoxic rats, ischemia-reperfusion resulted in a significant dose-dependent decrease in reduced GSH level when compared with euthyroid animals or animals that received a daily dose of $\mathrm{L}_{-} \mathrm{T}_{4}$ at $1.5 \mu \mathrm{g} / 100 \mathrm{~g} \mathrm{BW}$ per day $(\mathrm{T}+\mathrm{IR}$ versus $\mathrm{E}+\mathrm{S}, \mathrm{E}+\mathrm{IR}$, and $\mathrm{T}+\mathrm{S}, \mathrm{P}<0 \cdot 05$; Fig. $2 \mathrm{C})$.

\section{Discussion}

Though epidemiological cross-sectional studies do not reveal an association between thyrotoxicosis and hypertension or stroke (Qureshi et al. 2006, Völzke et al. 2006, Walsh et al. 2006, Wilson et al. 2006), a few case reports suggest its contribution toward post-ischemic damage. The fact that 

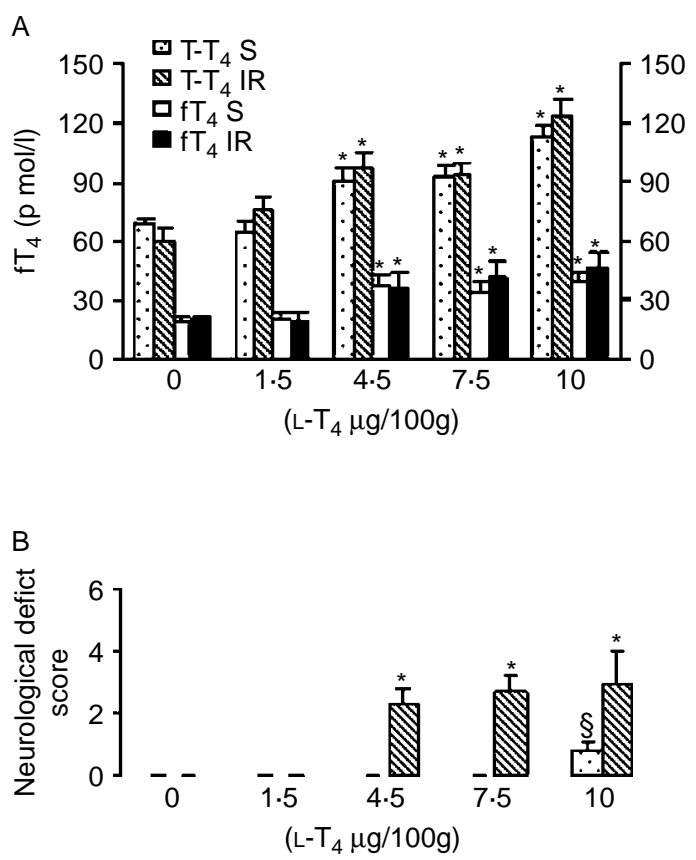

D

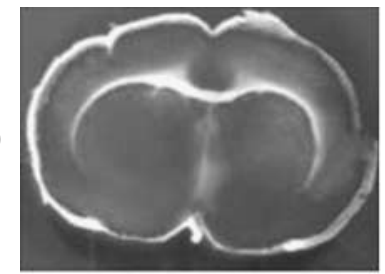

1.5

$S$

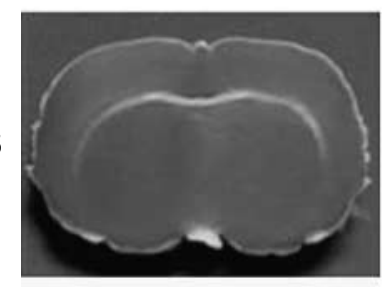

4.5
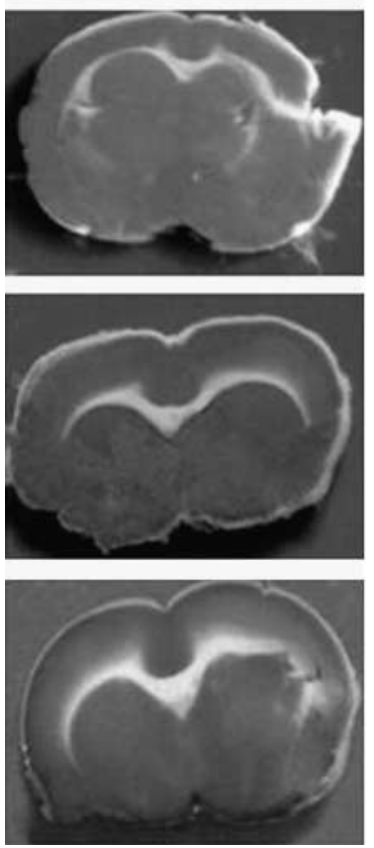

IR
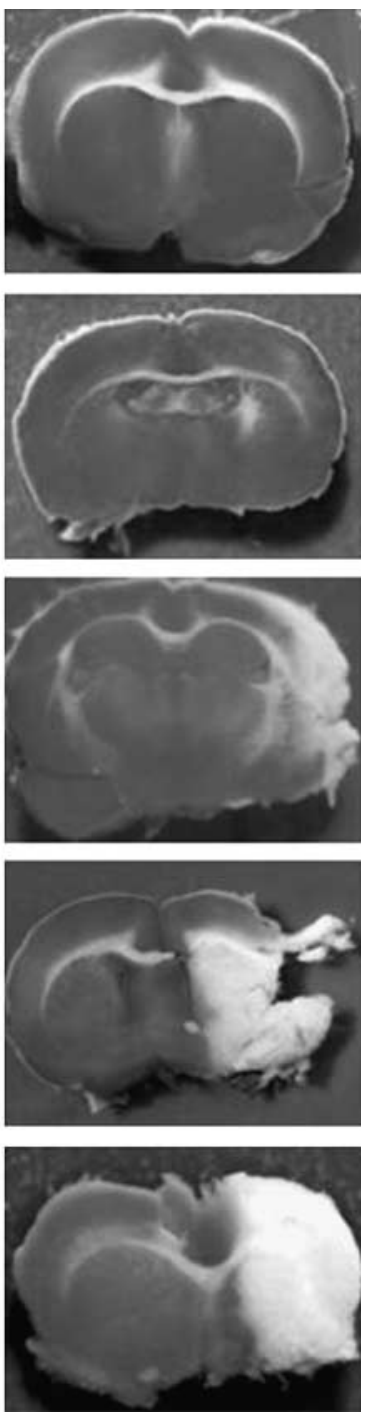

Figure 1 Effect of L-thyroxine on hormone levels, neurological deficit, and on infarct assessment after 30 min of ischemia followed by 3 days of reperfusion. Each point on the histograms represents mean \pm s.D. values. The number of animals used for neurological scores and serum hormone estimations, $n=6$ for all the groups. The number of tissue samples used for infarct assessment, $n=3$ for all the groups. In $\mathrm{B}$ and $\mathrm{C}$ the points on the $X$-axis represent thyrotoxic rats receiving different dosage of $\mathrm{L}-\mathrm{T}_{4}$ with sham-operated $(\mathrm{T}+\mathrm{S}$, dotted bar) and ischemia-reperfusion ( $T+I R$, hatched bar). Statistical significance was assessed by one-way ANOVA followed by SNK test. For histograms in (A), ${ }^{*} P<0 \cdot 05$ when comparisons were made between untreated group and treatment groups administered increasing dosage of $\mathrm{L}_{-} \mathrm{T}_{4}$ separately for circulating $\mathrm{fT}_{4}(\mathrm{pmol} / \mathrm{l})$ and $\mathrm{T}-\mathrm{T}_{4}(\mathrm{nmol} / \mathrm{l})$ levels. The histograms in (B) depict neurological deficit and in $(C)$ infarct volume respectively in sham-operated euthyroid $(E+S)$, thyrotoxic $(T+S)$ and ischemia-reperfused euthyroid $(E+I R)$, and thyrotoxic $(T+I R)$ rats. Comparisons made between the sham-operated euthyroid group $(E+S)$ and the group treated with $L-T_{4}$ at $10 \mu \mathrm{g} / 100 \mathrm{~g}(\mathrm{~T}+\mathrm{S})$ showed significantly increased neurological deficit and infarct volume in treatment group even on sham operation $\left({ }^{\S} P<0 \cdot 05\right)$. When comparisons were made between $\mathrm{E}+\mathrm{IR}$ group with $\mathrm{T}+\mathrm{IR}$ groups treated with $\mathrm{L}-\mathrm{T}_{4}$ at $4 \cdot 5,7 \cdot 5,10 \mu \mathrm{g} / 100 \mathrm{~g} \mathrm{BW}$ significant increase in neurological deficits and infarct volume $(* P<0 \cdot 05)$ was seen. (D) Effect of different dosage of thyroxine $\left(\mathrm{L}-\mathrm{T}_{4}, 1 \cdot 5\right.$, $4 \cdot 5,7 \cdot 5,10 \mu \mathrm{g} / 100 \mathrm{~g} \mathrm{BW}$, i.p.) after $30 \mathrm{~min}$ of ischemia-reperfusion on day 3 is shown in a representative photograph of TTC stained $2 \mathrm{~mm}$ thick coronal sections of rat brain; the unstained (white) areas represent the brain tissue infarct.

these epidemiological surveys do not show an association is not surprising given the relative rarity of strokes, compared with heart disease. These studies have too low a power to pick up any real effect on stroke rate. Thyrotoxicosis is associated with increased oxidative metabolism, and elevated free thyroxine indices in ischemic stroke patients have been reported (Olsson et al. 1990). Individuals with subclinical thyrotoxicosis appear to be at a greater risk of atrial fibrillation 

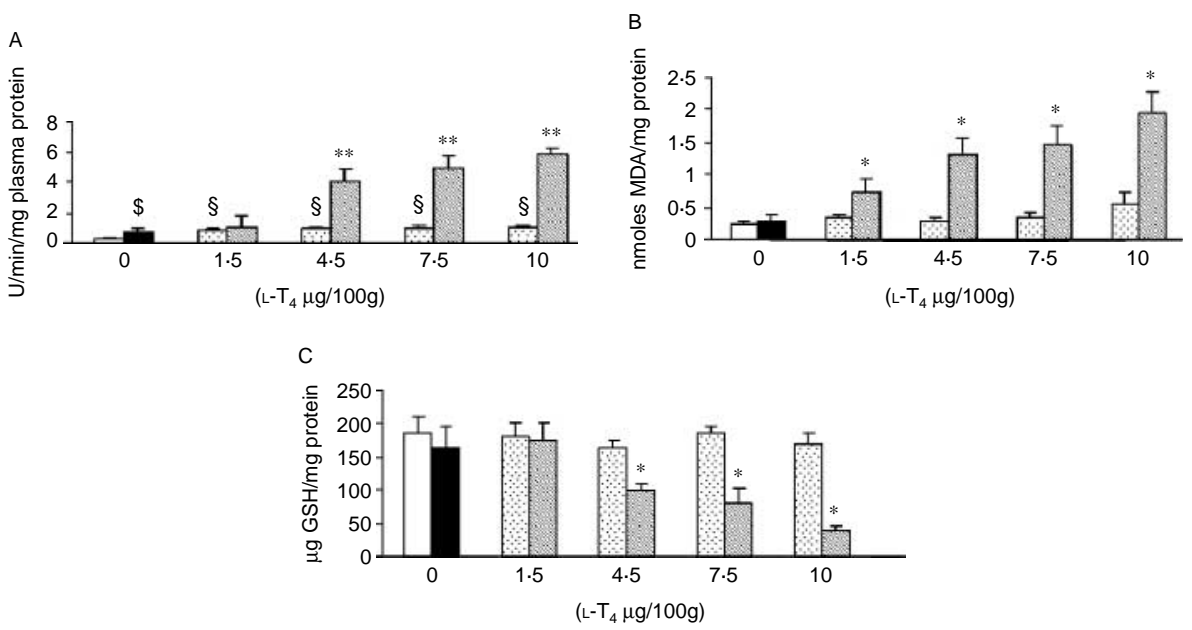

Figure 2 Effect of L-thyroxine on oxidative stress markers (A) lactate dehydrogenase activity (marker for necrosis/cell death) in plasma, (B) tissue MDA levels (lipid peroxidation), (C) tissue-reduced glutathione levels (antioxidant) after 30-min ischemia followed by 3 days of reperfusion. Results are presented as mean \pm s.D. ( $n=6$ for LDH activity, whereas $n=3$ for tissue MDA and GSH). The point ' 0 ' on the $X$-axis in the histograms represents euthyroid, sham-operated $(E+S$, unfilled bar) and ischemiareperfused rats $(E+I R$, filled bar). Other points on the $X$-axis represent thyrotoxic rats receiving the different dosage of $\mathrm{L}-\mathrm{T}_{4}$ compared with sham operation $(\mathrm{T}+\mathrm{S}$, dotted bars) and ischemia-reperfusion $(T+I R$, hatched bars). (A) A significant increase in LDH activity was observed when comparisons were made separately between euthyroid and treatment groups on a different dosage of $T_{4}(E+S$ and $T+S$ groups; $\left.{ }^{\S} P<0 \cdot 05\right),\left(E+S\right.$ and $\left.E+I R ;{ }^{\$} P<0 \cdot 05\right)$, and between (E+IR and $\left.T+I R ; * * P<0 \cdot 01\right)$ respectively. (B) A significant increase in MDA content was observed when comparisons were made between $E+I R$ and $T+I R$ groups treated with different dosages of $L-T_{4}$ separately $\left({ }^{*} P<0 \cdot 05\right)$. (C) A significant decrease in GSH levels were observed when comparisons were made between $E+I R$ and $\mathrm{T}+\mathrm{IR}$ groups treated with different dosage of $\mathrm{L}-\mathrm{T}_{4}$ separately $(* P<0 \cdot 05)$.

and possibly to its subsequent problems like stroke (Peterson \& Hansen 1988, Presti \& Hart 1989, Auer et al. 2001). Thyrotoxicosis through a hypercoagulable state may be a predisposing factor for cerebral vascular thrombosis (Maes et al. 2002). In this study, administration of $\mathrm{L}-\mathrm{T}_{4}$ per $100 \mathrm{~g}$ $\mathrm{BW}$ for 7 days in rats prior to ischemia-reperfusion resulted in a significant dose-dependent increase in circulating $T_{4}$ and $\mathrm{fT}_{4}$ levels except at the $\mathrm{L}-\mathrm{T}_{4}$ dose of $1.5 \mu \mathrm{g}$ wherein their levels remained within normal range. We observed a progressive increase in the infarct volume with an increase in the serum $\mathrm{T}_{4}$ levels with the corresponding thyroxin dose in rats. We show that the extent and amplitude of neurological damage after ischemia-reperfusion is more severe in thyrotoxic rats when compared with normal rats when exposed to 30-min MCA occlusion. We did not observe any macroscopic infarct following a 30-min occlusion in euthyroid rats. To our knowledge, this is the first comparative study of infarct size in overt thyrotoxicosis in rats. Our observation that MCA occlusion of 2-h duration results in $100 \%$ mortality in thyrotoxic rats is of significance. This is in contrast to $20 \%$ mortality in euthyroid rats following a $2-\mathrm{h}$ occlusion. The significant increase in infarct size and neurological deficits in dose-dependent $\mathrm{L}-\mathrm{T}_{4}$ administration is indicative of a greater degree of damage as a consequence of persistent thyrotoxicosis even when only 30-min MCA occlusion takes place. Although the association between thyrotoxicosis and cerebral vein thrombosis (CVT) has been reported in the early 1930s, it is unlikely that it can be explained only by thyrotoxicosis given the multifactorial pathogenesis of CVT. The case studies are only illustrative and do not refer to classical thrombotic stroke but they do refer to conditions such as vasculitis, large vessel atheroma, and venous thrombosis. Although the association between cerebral vascular thrombosis and thyrotoxicosis of various origins have been reported (Squizzato et al. 2005, Hsu et al. 2006), the exact etiology of minor infarct seen in rats on dose of $10 \cdot 0 \mu \mathrm{g} / 100 \mathrm{~g} \mathrm{BW}$ of $\mathrm{L}^{-\mathrm{T}_{4}}$ cannot be commented upon (Fig. 1D). Secondly, conclusive comments are also not warranted given the rarity of case reports describing cerebral ischemia in thyrotoxic subjects without cardiac arrhythmia (Squizzato et al. 2005). The extensive infarct on occlusion seen in rats on a high dosage of thyroxin may result from both the combined effect of resultant atrial fibrillation and a hypercoagulable state, but needs further investigation. The significant increase in lipid peroxidation and LDH activity in a dose-dependent manner also indicates a greater degree of damage as a consequence of persistent thyrotoxicosis. The findings are consistent with the reported induction of lipid peroxidation by $\mathrm{L}^{-\mathrm{T}_{4}}$ in brain homogenate (Wiktorska et al. 2005). We also show a dose-dependent decrease in reduced GSH levels as an indicator of the loss of self-defense under thyrotoxic condition. The results of the present study along 
with our earlier study in rats made hypothyroid prior to ischemia-reperfusion makes the point that oxidative stress markers and antioxidant levels alter depending on the thyroidal status of rats that underwent ischemia reperfusion (Rastogi et al. 2006). Thus, the results of both studies taken together indicate that thyroidal status alone may not contribute to the etiology of strokes, but is of importance in deciding the extent of damage or protection subsequent to its precipitation. Thyrotoxicosis-mediated post-ischemic cerebral damage seems to be secondary to its ability to keep the neural tissues in a state of hyperactivity condition through the reported high levels of circulating biogenic amines, including glutamic acid in thyrotoxic patients (Upadhyaya et al. 1992). The increased availability of 3,5,3'-triiodothyronines $\left(T_{3}\right)$ is central to the plausible release of biogenic amines. Type $2,5^{\prime}$-deiodinase $\left(5^{\prime}\right.$-D2 $)$, which converts thyroxine to the more active $\mathrm{TH} \mathrm{T}_{3}$, is believed to be an important source of intracellular $\mathrm{T}_{3}$ in the brain (Bianco et al. 2002). Increased cerebral Type 2 deiodinase expression mainly localized in astrocytic cell bodies with possible generation of $\mathrm{T}_{3}$ under ischemic insult in unlesioned euthyroid rats has been reported (Margaill et al. 2005). Astrocytic up-regulation of $5^{\prime}$-D2 mRNA suggests a potential role of $\mathrm{T}_{3}$ action in the adult brain's response to injury and recovery (Zou et al. 1998). The possibility that astrocytic cell bodies are getting exposed to a high amount of $\mathrm{T}_{3}$ under the compound insult of thyrotoxicosis and ischemia needs to be investigated.

Our results help to explain the observation of many case reports indicating a greater degree of neurological damage seen in stroke patients harboring preexisting thyrotoxicosis of various etiologies (Smith et al. 1994, Rocha et al. 2001, Mouton et al. 2005, Tsai et al. 2006), and a better outcome on correction of their thyroidal disease (Tsai et al. 2006). How the TH mediates the stroke outcome is not clear at present. It seems to be secondary to its primary effect of either keeping the neural tissues in a state of sluggishness or hyperactive condition. This hypothesis is supported by the observations that per se TH does not contribute to the etiology of stroke but needs to be tested. The results from this study also point toward the necessity of monitoring the thyroidal status of all the subjects harboring other risk factors for precipitation of strokes, and to take corrective measures to avoid or prevent severe post-ischemic damage.

\section{Acknowledgements}

The equipment grant (FIST) to $M \quad M \quad G$ from the Department of Science and Technology, Government of India (SR/FIST/LS-II-018/2003) and the senior research associate ship to $\mathrm{L} \mathrm{R}$ from the Council of Scientific and Industrial Research, New Delhi (13 (7985-A)/2005-pool)) are duly acknowledged. The authors declare that there is no conflict of interest that would prejudice the impartiality of this scientific work.

\section{References}

Adamo AM, Llesuy SF, Pasquini JM \& Bovers A 1989 Brain chemiluminescence and oxidative stress in hyperthyroid rats. Biochemical Journal $263273-277$.

Alevizaki M, Synetou M, Xynous K, Alevizaki CC \& Vemmos KN 2006 Hypothyroidism as a protective factor in acute stroke patients. Clinical Endocrinology 65 369-372.

Auer J, Scheiber P, Mische T, Langsteger Eber O \& Eber B 2001 Subclinical hyperthyroidism as a risk factor for atrial fibrillation. American Heart Journal $142838-842$.

Bederson JB, Petts LH, Germano SM, Nishimura MC, Davis RL \& Bartkowski HM 1986 Evaluation of 2,3,5 tri phenyltetrazolium chloride as a stain for detection \& quantification of experimental cerebral infraction in rats. Stroke 17 1304-1308.

Beutlin E, Duron O \& Kelly BM 1969 Improved method for estimation of blood glutathione. Journal of Laboratory and Clinical Medicine 61 882-887.

Bianco AC, Salvatore D, Gereben B, Berry MJ \& Larsen PR 2002 Biochemistry, cellular and molecular biology, and physiological roles of the iodothyronine selenodeiodinases. Endocrine Reviews 23 38-89.

Bulesta BA, Bulesta VI, Pashchenko AE, Magela RM \& Korshinskii IIU 1981 Participation of the thyroid gland in the mechanism of development of cerebral circulatory disorders. Zhurnal Nevropatologii i Psikhiatrii Imeni S.S. Korsakova 81 1301-1304.

Hsu SW, Chaloupka JC \& Fattal D 2006 Rapidly progressive fatal bihemispheric infarction secondary to Moyamoya syndrome in association with Grave thyrotoxicosis. American Journal of Neuroradiology 27 643-647.

Kalmijn S 2000 Sub clinical hyperthyroidism and risk of Dementia. The Rotterdom study. Clinical Endocrinology 53 733-737.

Kapaki E, Paraskevas GP, Montzou E, Papapostolou A, Alevizaki M \& Vassilopoulos D 2006 Thyroid function in patient with Alzheimer disease: implication to anticholinesterase treatment. Alzheimer Disease and Associated Disorders 20 242-247.

Lowry OH, Rosebrough NJ, Farr AL \& Randall R 1951 Protein measurement with the folin phenol reagent. Journal of Biological Chemistry $193265-275$

Maes J, Michotte A, Velkeniers B, Stadnik T \& Jochmans K 2002 Hyperthyroidism with increased factor VIII procoagulant protein as a predisposing factor for cerebral venous thrombosis. Journal of Neurology, Neurosurgery, and Psychiatry 73 456-459.

Margaill I, Royer J, Lerouet D, Ramaugé M, Le Goascogne C, Li WW, Plotkine M, Pierre M \& Courtin F 2005 Induction of type 2 iodothyronine deiodinase in astrocytes after transient focal cerebral ischemia in the rat. Journal of Cerebral Blood Flow and Metabolism 25 468-476.

Mouton S, Nighoghossian N, Berruyer M, Derex L, Philippeau F, Cakmak S, Honnorat J, Hermier M \& Trouillas P 2005 Hyperthyroidism and cerebral venous thrombosis. European Neurology 54 78-80.

Okhawa H, Ohishi N \& Yagi K 1979 Assay for lipid peroxides in animal tissue by thiobarbituric acid reaction. Analytical Biochemistry 95 351-358.

Olsson T, Asplund K \& Hagg E 1990 Pituitary-thyroid axis, prolacrin and growth hormone in patients with acute stroke. Journal of Internal Medicine 228 287-290.

Peterson P \& Hansen JM 1988 Stroke in thyrotoxicosis with atrial fibrillation. Stroke 19 15-18.

Presti C \& Hart RG 1989 Thyrotoxicosis, atrial fibrillation and embolism, revisited. American Heart Journal 117 976-977.

Qureshi AI, Suri FK, Nasar A, Kirmani JF, Divani AA \& Giles WH 2006 Free thyroxine index and risk of stroke: results from the National Health and Nutrition Examination Survey Follow-up Study. Medical Science Monitor 12 501-506.

Rastogi L, Godbole MM, Ray M, Rathore P, Pradhan S, Gupta SK \& Pandey CM 2006 Reduction in oxidative stress and cell death explains hypothyroidism induced neuroprotection subsequent to ischemia/reperfusion insult. Experimental Neurology 200 290-300.

Rocha MS, Brucki SM \& Ferraz AC 2001 Cerebral vasculitis and BasedowGrave's disease: report of two cases. Arquivos de Neuro-Psiquiatria 59 948-953. 
Shuaib A, Ijaj S \& Hemmings S 1994 Decreased glutamate release during hypothyroidism may contribute to protection in ischemia. Experimental Neurology 128 261-265.

Smith CD, Ain KD, Ryan S \& Ngai BC 1994 Systemic embolism in thyrotoxicosis without cardiac arrhythmia. Thyroid 4 209-211.

Squizzato A, Gerdes VEA, Brandjes DPM, Buller HR \& Stam J 2005 Thyroid diseases and cerebrovascular disease. Stroke 36 2302-2310.

Tsai MH, Tan TY, Kuo YL \& Chang KC 2006 Multiple intracranial arterial stenosis in association with thyrotoxicosis: a case report. Acta Neurologica Taiwanica 15 105-108.

Upadhyaya I, Agrawal JK, Dubey GP \& Udupa KN 1992 Biogenic amines and thyrotoxicosis. Acta Endocrinologica 126 315-318.

Völzke H, Alte D, Dörr M, Wallaschofski H, John U, Felix SB \& Rettig R 2006 The association between subclinical hyperthyroidism and blood pressure in a population-based study. Journal of Hypertension 24 1947-1953.

Walsh JP, Bremner AP, Bulsara MK, O'Leary P, Leedman PJ, Feddema P \& Michelangeli V 2006 Subclinical thyroid dysfunction and blood pressure: a community-based study. Clinical Endocrinology 65 486-491.

Wiktorska JA, Lewinski A \& Sewerynek E 2005 Effects of different antioxidants on lipid peroxidation in brain homogenates, induced by L-thyroxine administration in rats. Neuro Endocrinology Letters 26 704-708.
Wilson S, Parle JV, Roberts LM, Roalfe AK, Hobbs FD, Clark P, Sheppard MC, Gammage MD, Pattison HM, Franklyn JA \& Birmingham Elderly Thyroid Study Team 2006 Prevalence of subclinical thyroid dysfunction and its relation to socioeconomic deprivation in the elderly: a community-based cross-sectional survey. Journal of Clinical Endocrinology and Metabolism 91 4809-4816.

Wroblewski F \& La Due JS 1955 Lactate dehydrogenase activity in the blood. Proceedings of the Society for Experimental Biology and Medicine 90 210-215.

Zea-Longa E, Weinstein PR, Carlson S \& Cummins R 1989 Reversible middle artery occlusion without craniotomy in rats. Stroke 20 84-91.

Zou L, Burmeister LA, Styren SD, Kochanek PM \& DeKosky ST 1998 Up-regulation of type 2 iodothyronine deiodinase mRNA in reactive astrocytes following traumatic brain injury in the rat. Journal of Neurochemistry $71887-890$.

Received in final form 21 November 2007

Accepted 23 November 2007

Made available online as an Accepted Preprint

23 November 2007 